\title{
EL ESPACIO VITIVINÍCOLA ARAGONÉS COMO PAISAJE CULTURAL Y FACTOR DE DESARROLLO
}

\author{
Luisa Ma Frutos Mejías, Ana Castelló Puig, Ma Luz Hernández Navarro, \\ Blanca Loscertales Palomar, Enrique Ruiz Budría \\ y Pascual Rubio Terrado \\ Grupo GEDETUZ. Departamento de Geografía y Ordenación del Territorio \\ Instituto Universitario de Ciencias Ambientales IUCA \\ Universidad de Zaragoza \\ Imfrutos@unizar.es
}

\begin{abstract}
Resumen: En el momento actual el paisaje cultural, formado por elementos tangibles e intangibles que expresan una acción humana prolongada sobre el medio natural, es considerado como patrimonio y seña de identidad de una sociedad y un territorio. Igualmente se entiende como un recurso que permite actividades económicas y repercute en esa sociedad y ese territorio. Los paisajes vitivinícolas cumplen esos requisitos. En las siguientes páginas, partiendo de los datos que ofrecen las fuentes de información del Ministerio de Agricultura, Alimentación y Medio Ambiente, el Departamento de Agricultura del Gobierno de Aragón, el Instituto Aragonés de Estadística y los Consejos Reguladores de las Denominaciones de Origen vitivinícolas, se analizarán los espacios de viñedo aragoneses con denominación de origen, donde se concentra el mayor porcentaje de este cultivo en Aragón, poniendo la atención en el carácter patrimonial y cultural que aporta la larga historia de sus paisajes y su papel en el desarrollo rural.
\end{abstract}

Palabras clave: paisaje vitivinícola, patrimonio cultural, denominaciones de origen, Aragón.

Abstract: At present, the cultural landscape, made up of tangible and intangible elements expressing as it does a prolonged human action on the natural environment, is viewed not only as heritage but as the identity of

Recibido: 28-05-12. Aceptado: 31-05-13. 
a society and territory. It is also seen as a resource that enables economic activities to take place and has an impact both on society and on this territory. The wine landscapes meet those requirements. In the following pages, from data that provide sources of information taken from the Ministry of Agriculture, Food and Environment, the Department of Agriculture of the Government of Aragon, the Aragonese Institute of Statistics and the tip regulators of the designation of origin wine, the Aragonese spaces of vineyard with designation of origin will be analyzed, which make up the largest percentage of this crop in Aragon with special emphasis on to the patrimonial character that the long history of its landscapes and their role in rural development has contributed.

Key words: wine-growing landscape, cultural heritage, denomination of Origin, Aragon.

\section{Introducción: el paisaje como patrimonio y bien económico}

El paisaje es un concepto polisémico, pero desde el punto de vista geográfico o antropológico es la expresión visualmente perceptible del arreglo u orden de los elementos naturales y culturales integrantes del sistema territorial. Constituye una realidad compleja, formada por elementos tangibles e intangibles, cuya combinación otorga el carácter que lo identifica como tal y es el resultado de la acción antrópica sobre los componentes del medio natural. Por ello, el paisaje cultural deriva de la percepción que suscitan los elementos culturales localizados en un entorno natural (Sabaté, 2004), del que, según Zouain (2007), no son independientes ni en su significación, ni en su aprovechamiento, ni en su valor total, puesto que ese entorno es un elemento activo. De hecho, constituye el producto más elaborado en un espacio concreto sobre el que un grupo humano ha proyectado su cultura. (Martínez, 2006).

En las últimas décadas, la amenaza de destrucción de algunos paisajes y la banalización de otros hace que sea necesaria la protección de aquellos que tienen valor como patrimonio cultural, entendido este concepto como el conjunto de bienes y derechos heredados, propiedad de una persona, institución o sociedad. Por ello, la Convención sobre el Patrimonio Mundial, Cultural y Natural elaboró un documento, adoptado por la UNESCO en 1972 (Conferencia Internacional de la ONU, Paris, 1972), incorporando la categoría de paisaje cultural como patrimonio, entendiendo que ilustra la evolución de la sociedad humana y sus asentamientos a lo largo del tiempo, condicionados por su entorno y por la acción de fuerzas sociales, económicas y culturales, tanto internas como externas. Para ello se creó un instrumento jurídico internacional para identificar, proteger, conservar y legar a las generaciones futuras dicho patrimonio (Rössler, 1998). Así mismo, se especificaron tres tipos de paisaje: los creados y diseñados intenciona- 
damente por razones estéticas; los evolucionados orgánicamente, bien sean relictos, si el proceso evolutivo ya ha concluido pero sus rasgos característicos son todavía visibles materialmente, o activos, continuos en el tiempo, si ese proceso sigue dinámico; los asociativos, con asociación religiosa, artística o cultural al medio natural.

A la segunda categoría de "paisajes orgánicamente desarrollados, activos y con continuidad en el tiempo" pertenecerían tanto los arrozales asiáticos en terraza como los viñedos europeos y aunque se reconoció en sucesivas reuniones que Europa poseía numerosos paisajes culturales, en esta primera etapa se incluyeron muy pocos, para preservar el equilibrio con otras partes del mundo (Róssler, 1998: 50-51). No obstante, la mayoría de los nominados se sitúan en Europa y Asía, pudiendo citarse entre ellos la región vinícola del Alto Duero, en Portugal, nominada Patrimonio de la Humanidad.

La necesidad de reconocer esa riqueza de los paisajes culturales europeos ha supuesto que en fecha más reciente, a iniciativa del Comité de Ministros del Consejo de Europa, un grupo de expertos, reunidos en Florencia en octubre del 2000, acordaran un documento llamado Convenio Europeo del Paisaje (Comisión Europea, 2000), el primero con valor normativo referido exclusivamente a Europa, que entró en vigor en marzo de 2004 y ha sido ratificado ya por la mayoría de los países europeos, entre ellos España (Zoido, 2004). El concepto de paisaje cultural que se asume es el ya expuesto más arriba, señalando también que dicho documento debe ser considerado como un complemento de otros, sobre todo los elaborados por la UNESCO, citados ya. El texto del Convenio Europeo del Paisaje se complementa con las Recomendaciones y Medidas para su Aplicación, adoptadas por el Consejo de Ministros en 2008. En ese documento se reconoce la importancia de los paisajes europeos como patrimonio, como recurso, como señas de identidad de sus habitantes y va más allá que todo lo que anteriormente se había planteado, tal como pone de manifiesto Zoido (2004), al considerar paisaje "todo el territorio" (artículo 2, dedicado al ámbito de aplicación), sobrepasando una perspectiva meramente proteccionista al exigir no sólo la protección y conservación, sino también la gestión y ordenación, territorializando el concepto y asociándolo a la cultura de un pueblo. Así, entre otros se incluyen los paisajes agrarios, de los que forma parte el paisaje vitívinícola.

En definitiva, se asume que el paisaje es una construcción socio-cultural acumulativa diacrónica, un palimpsesto de su propia historia, lo que permite señalar la existencia de una cultura territorial en interacción con el espacio donde ocurre, pero sin olvidar que cualquier paisaje cultural constituye un estado temporal de equilibrio hombre-medio-cultura, frágil e inestable y cualquier intervención ulterior sobre alguno o algunos de sus componentes -sea por acción o por omisión- origina un paisaje nuevo. También es inestable su valor de uso, porque difícilmente puede soportar un aprovechamiento diferente que el que conduce a percibirlo como paisaje cultural de cierto valor; su capacidad como elemento potencial de desarrollo territorial se debe a la combinación de los valores de uso y de significación. De otro lado, en el sentido de cons- 
trucción mental con determinada carga simbólica, deriva de los caracteres del territorio y tiene un carácter de herencia que justifica su consideración como patrimonio territorial correspondiente a un espacio/sociedad particular.

Aunque no existe ningún patrón normativo para determinar con rigor qué es o no es un paisaje cultural, el valor y la significación que se le adjudica tiende a depender de las características de sus componentes, de los usos que se dan en él, del carácter e impronta histórica que rodea su origen, de su singularidad o rareza, de lo que representa y de las vivencias e imágenes que proyecta en el observador. Además, el patrimonio paisajístico, como resultado de la acción humana, es el fiel reflejo de un modo y un medio de vida con implicaciones socioeconómicas. Puede asignársele también la capacidad de servir como materia prima para el disfrute cultural y/o de ocio de las sociedades modernas, convirtiéndose así en un recurso potencial de desarrollo económico mediante la oferta de un turismo alternativo al de masas (turismo verde, agroturismo, turismo cultural, ecoturismo, entre otros) y también social, si el consumo lo realiza prioritariamente la población local y le sirve para reforzar su identidad como grupo o lo emplea como elemento educativo.

La interpretación, conservación y mercantilización del patrimonio territorial, en definitiva su patrimonialización, figuran en la literatura académica como actividades dinamizadoras de las economías locales, por sus efectos positivos sobre la generación de empleo, por su incidencia favorable sobre las dotaciones de servicios competitivos y de equipamientos públicos y por las posibilidades que ofrece para el aprovechamiento y revalorización de recursos (Francés, 2006) y de protección y conservación de los mismos. Y es que, parafraseando a Graham et al. (2000), el patrimonio otorga poder y genera actividad económica, por lo que se considera un agente y bien económico, con valor de uso directo, en el sentido de generar ingresos (Castelló y Giné, 2007; Rubio y Hernando, 2007), así como de identidad social, por lo que hay que protegerlo para garantizar un uso equilibrado y sostenible del mismo, ya que la sostenibilidad ambiental y social del patrimonio territorial, por su carácter general de recurso no renovable, pocas veces está garantizada (Domínguez y Cuenca, 2005; Ose, 2009; Rubio, 2010).

Aunque se insiste más en los aspectos positivos de esa patrimonialización que en los negativos, no podemos olvidar los segundos, entre los que hay que subrayar los que pueden provocar un proceso de pérdida de los valores culturales iniciales, impulsar la mercantilización y cierta banalización de las tradiciones locales, fomentar la especulación sobre el suelo e incluso, lo que es más importante en términos territoriales, impactar sobre el medio ambiente y la cohesión social y sustituir el uso tradicional del espacio, precisamente el que se encuentra en la base de la elaboración del paisaje que se valoriza, por otro nuevo. En realidad, la sostenibilidad ambiental y social del uso turístico del patrimonio territorial, por su carácter general de recurso no renovable, pocas veces está garantizada (Ose, 2009). En definitiva, las posiciones sobre la sostenibilidad del uso turístico del patrimonio territorial enfrentan a quienes ponen el énfasis 
en su capacidad modificadora, igual que cualquier otra actividad económica, y a quienes lo hacen en los beneficios sociales y económicos de dicha actividad y su capacidad para activar mecanismos de protección, del que es su bien primario el propio patrimonio territorial, alimentando así el dinamismo y la sostenibilidad.

Los paisajes vitivinícolas europeos cumplen todos los requisitos citados hasta ahora: tienen arraigo histórico y estrecha relación con el medio natural, ya que forman parte del mosaico agrícola mediterráneo en el que se combinan la clásica trilogía de trigo, vid y olivo y configuran un sistema de paisaje cultural, territorializado (Bertrand, 2008), que se articula en torno a un núcleo habitado, bien definido. En ese sistema, los viñedos, como resultado de una obra humana, individual y colectiva a lo largo de generaciones, adquieren personalidad propia, constituyendo un espacio paisajístico "que hoy se percibe como depositario de formas de vida, de tradición y de una ancestral relación con el medio natural", (Pintó i Fosalba, 2008: 5). Pero además, como afirma Tinlot (2006), el paisaje vitivinícola tiene una naturaleza polifacética, combinando las viñas, las bodegas y otras construcciones humanas, en las que se reflejan los recursos de cada región. El marco y la densidad de la plantación, la morfología del parcelario, la selección de las cepas, el modo de cultivo, son el resultado de un compromiso entre la naturaleza y el saber hacer del agricultor que no solo reflejan un modo de vida, sino que forman parte integrante de su economía.

En las últimas décadas, estos paisajes son objeto de análisis desde diferentes perspectivas, en el contexto de la multifuncionalidad del medio rural, en el que se presta una especial atención a la calidad y las especificidades territoriales en la producción. Participa en todas las estrategias de desarrollo, porque se considera un recurso importante: por su valor agroecológico, por su protagonismo en el mundo agroindustrial, donde lo cuantitativo y lo cualitativo van parejos en la consecución de la competitividad, y como elemento catalizador de sinergias con otras actividades, industriales y de servicios, favoreciendo especialmente el desarrollo turístico. La identificación de esos paisajes vitivinícolas como recurso, patrimonio y legado cultural es, pues, un primer paso para fomentar acciones de protección.

De hecho, la vitivinicultura forma parte de una actividad económica que, en determinados espacios rurales, ha pasado a ser la base de su desarrollo, asociada de modo indisoluble a la industria de producción de vino, también con un indudable papel social, pues fija la población y permiten una mejor distribución de la renta (Albisu,1998). El análisis de este paisaje y su repercusión socioeconómica territorial es hoy pertinente, porque en los viejos países europeos exportadores se constata una crisis a la que intentan responder viticultores, empresarios del sector, economistas y enólogos, pero que, desde una óptica geográfica, afecta a verdaderos complejos multidimensionales, fuertemente inscritos en el territorio a lo largo del tiempo (Pereira, 2006). Si se analizan los cambios acaecidos en el binomio cultivo-producción de vino en las DO a la luz de la Teoría de las Convenciones, criterios que determinan las decisiones de los productores 
y los consumidores en torno a la calidad, y la Teoría de los Mundos de Producción, combinaciones de tecnologías, mercados, cualidades de los productos y estilos de utilización de los recursos, (Lindkvist y Sánchez, 2007), en las últimas décadas se ha producido un cambio desde los procesos de producción tradicionales hacia innovaciones que conducen a nuevas convenciones y mundos de producción, cuya reflejo en el paisaje es patente, sin que por ello hayan perdido por completo su esencia cultural. De la misma manera se han establecido redes complejas entre los viticultores, las bodegas y las instituciones, con un sistema de gobernanza a nivel normativo, organizativo y productivo, cuya preocupación principal es conseguir calidad y promoción, mediante la innovación y la comunicación, como ponen de manifiesto Aparicio et al. (2003) para Castilla y León.

En suma, puede plantearse como hipótesis de trabajo el hecho histórico de que en torno al cultivo de la vid y de la elaboración del vino en las bodegas ha surgido toda una cultura que puede leerse en el paisaje, particularmente visible en las zonas con indicaciones geográficas, como son las Denominaciones de Origen Protegidas DOP) y los Vinos de la Tierra (VT) cuyas características han favorecido un desarrollo endógeno sostenible y dinámico, que mantiene vivo el medio rural. En los siguientes apartados la atención se centrará solamente en las demarcaciones DOP, en las que se tratará de mostrar que la vitivinicultura configura en ellas unos paisajes que cumplen los requisitos para ser considerado patrimonio cultural y motor de desarrollo local.

\section{Método y fuentes}

No se trata aquí de analizar los componentes de esos paisajes con los métodos al uso para alcanzar su definición, sino de subrayar las características que permiten asignarle un valor patrimonial y cultural y poner de relieve su utilización como recurso económico. Es, por tanto, un método eminentemente descriptivo, apoyado en las fuentes de información obtenidas del Ministerio de Agricultura, Alimentación y Medio Ambiente (MAGRAMA), del Departamento de Agricultura de la Diputación General de Aragón (Anuarios de Estadística Agraria, Documentos 1T), del Instituto Aragonés de Estadística (IAEST) y de las Consejos Reguladores de las Denominaciones de Origen vitivinícolas.

Entre las características a destacar se considerará su impronta en el paisaje rural, con áreas de cuasi monocultivo, calificadas en algunas ocasiones como "mar de vides" (Ferrer Regales, 1957), y la actual concentración en determinadas comarcas que han obtenido la Denominación de Origen Protegida (DOP), sin que eso suponga establecer criterios de calidad universales; se incidirá en el carácter histórico de este cultivo y su elaboración, lo que ha permitido desarrollar una verdadera cultura del vino, con fuertes implicaciones socioeconómicas y ambientales. Igualmente se hará referencia a su peso actual en la economía local en relación con el trabajo, la renta y la participación en el mercado. 


\section{El paisaje vitícola en Aragón}

Las tierras vitícolas aragonesas gozan de esa cualidad de paisaje histórico, heredado y, por lo tanto, cultural y han orientado la actividad económica de sus habitantes donde se han mantenido como predominantes. Los viñedos se localizan en la mayor parte del territorio regional, con la excepción de las zonas más montañosas o de elevada altitud, donde las condiciones climáticas limitan su crecimiento. Esta dispersión puede apreciarse en la figura 1, que expresa el porcentaje de la superficie dedicada a viñedos en relación con el total de tierra cultivada, pero igualmente se aprecia la actual concentración de tierras vitícolas en determinadas comarcas.

La historia del cultivo de la viña en Aragón es larga. Hay noticias desde la época romana, pero especialmente desde la Edad Media, cuya expansión queda documentada en los numerosos contratos de arrendamiento ad plantandum, en el que el propietario exigía al arrendador la plantación de cepas, especialmente en las zonas de regadío, donde los rendimientos eran más seguros, en numerosos documentos posteriores y en alusiones en la literatura, desde el Quijote al Romanticismo al menos (Casanova, 2008; Marías, 2005; Lacarra, 1960; Ledesma, 1958; Asso, 1748, reedit. 1947). Pero estos paisajes constituyen un elemento clave en algunas comarcas a partir del siglo XVIII y, sobre todo, desde finales del XIX, a raíz de la destrucción del viñedo francés por la filoxera. La superficie ocupada por el viñedo alcanzó su máxima extensión en Aragón entre 1877 y 1900 , con 145.500 ha.

Posteriormente, al atacar la filoxera también a las plantaciones aragonesas, y recuperado el cultivo en Francia, se reduce esa superficie, de tal modo que nunca se volvió a alcanzar la misma cifra (Asso, 1748, reedit.1947; Ferrer Regales, 1957; García Manrique, 1960; Estella, 1981 y 1982; Frutos, 1982; Chueca, 1972; Lorente y Barbacil, 2004).

En los últimos decenios la evolución de la superficie de los viñedos aragoneses, al igual que en otras zonas de España y Europa, ha sido negativa en su conjunto, pasando de más de 100.000 ha a algo menos de 50.000 ha (figura 2), pues donde constituía un complemento de subsistencia el cultivo se ha ido abandonando, tanto por su escasa rentabilidad como por la enorme pérdida de población del medio rural. Sin embargo mantiene su presencia el la mayor parte del territorio (figura 1), concentrándose especialmente en determinadas áreas, y en los últimos años se ha estabilizado e incluso se ha incrementado en el regadío, al levantarse la prohibición de regar este cultivo. La política de la Unión Europea en relación con el vino no ha sido ajena al descenso de la superficie de viñedo, ya que en Aragón ha estado siempre estrechamente relacionado con su elaboración, pues prácticamente la totalidad de la producción de uva se dedica e esa transformación (tabla 1).

Sin duda la mayoría de estos viñedos no son muy extensos -el censo de 1999 ponía de manifiesto que el $45 \%$ de la superficie de viñedo se cultivaba en explotaciones 


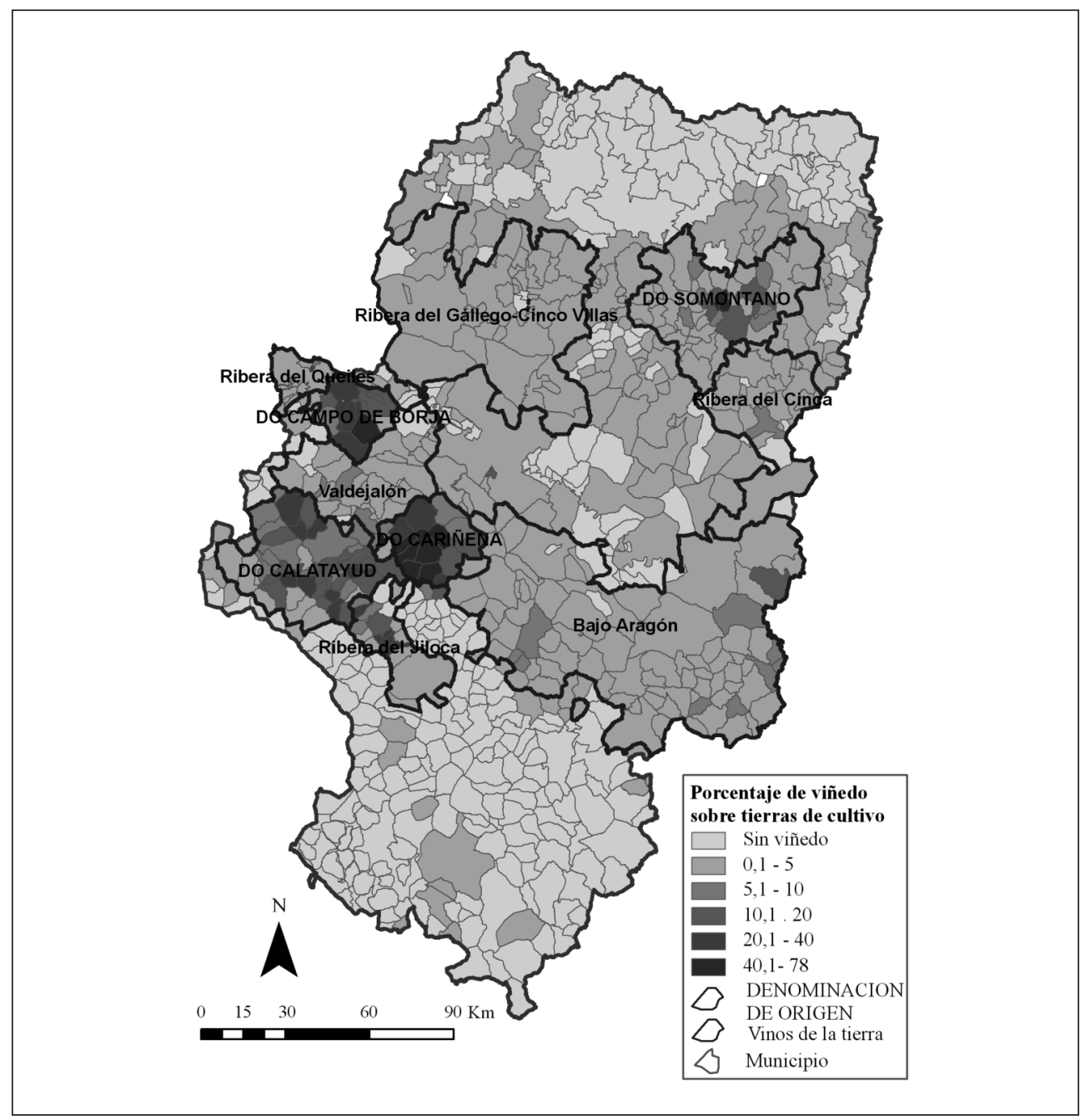

Figura 1. Extensión del viñedo en Aragón y delimitación de áreas con Indicación Geográfica.

Fuente: Cuestionarios IT. Gobierno de Aragón. Elaboración propia.

inferiores a 20 ha-, pero en las comarcas en las que las tierras ocupadas por la vid se concentran, ofrecen un paisaje específico que domina sobre otros cultivos, especialmente los piedemontes pirenaico e ibérico y, en menor medida, el valle medio del río Jalón, en torno a Calatayud, y algún sector del río Cinca. Estos paisajes constituyen una herencia cultural extraordinaria y son en la actualidad un recurso fundamental para el desarrollo de esas áreas rurales (tabla 2). 
Tabla 1. Superficie y explotaciones dedicadas a viñedos en Aragón

\begin{tabular}{|l|c|c|c|c|}
\hline Destino de la uva & Hectáreas & \% hectáreas & Explotaciones & \% explotaciones \\
\hline Uva para vinificación & 45.462 & 99,7 & 7.807 & 96,1 \\
Uva de mesa & 124 & 0,3 & 315 & 3,9 \\
Totales en producción & 45.586 & 100 & 8.122 & 100 \\
\hline Superficie abandonada & 703 & \\
\hline
\end{tabular}

Fuente: Registro vitivinícola de Aragón. Instituto Estadístico de Aragón. 2008.

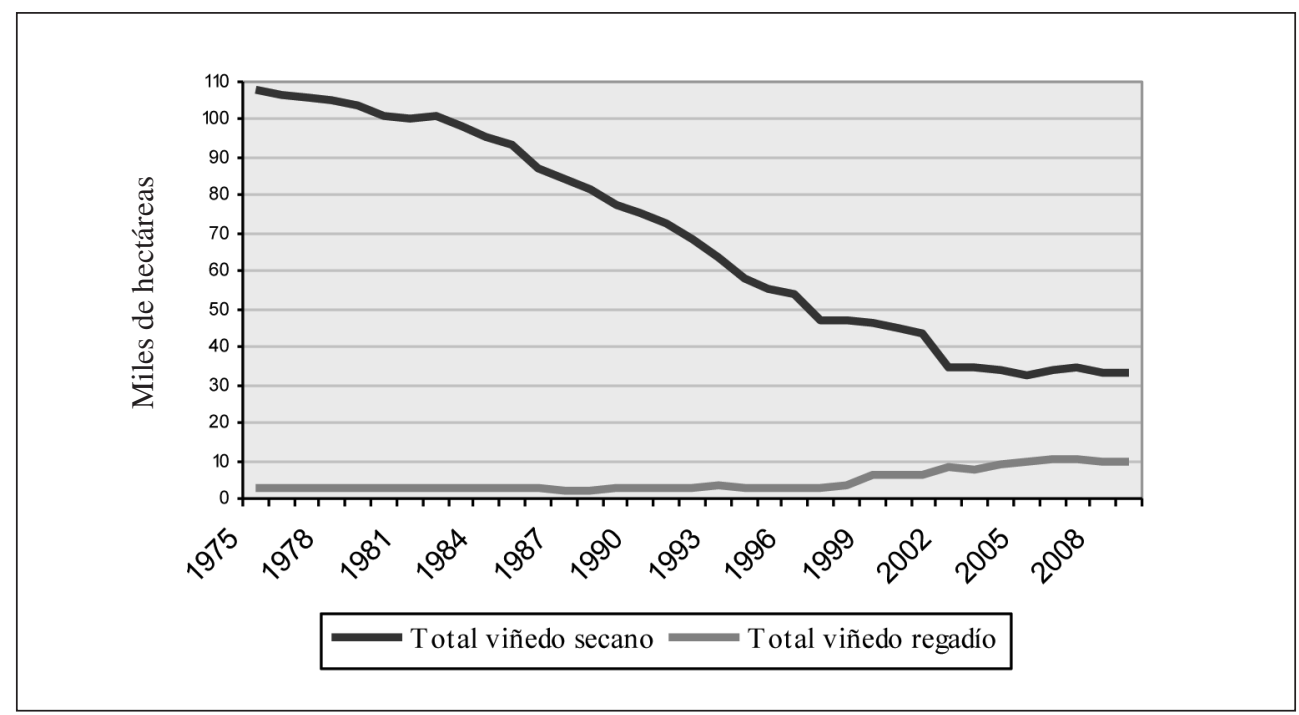

Figura 2. Evolución de la superficie de viñedo en Aragón. 1975-2008. Fuente: DGA. Departamento de Agricultura. Formularios 1T. Elaboración propia.

Algunas de las variedades que hoy se cultivan se han introducido recientemente, pero muchas son autóctonas, entendiendo como tales, según los expertos, no solo las nativas o endémicas sino también aquellas de las que hay indicios de haber sido introducida, en general, en periodo anterior a la filoxera (Domingo, 2009). En la tabla 3 se incluyen las variedades más extendidas en Aragón, cuya existencia está datada desde hace varios siglos (Lorente y Barbacil, 2004), lo que da fe de la importancia cultural de este paisaje y su tradición histórica. 
Tabla 2. Zonas de concentración del viñedo en Aragón

\begin{tabular}{|l|c|c|}
\hline Demarcaciones con Denominación de Origen & Hectáreas & \% del total has \\
\hline Calatayud & 6.687 & 14,1 \\
Somontano & 6.937 & 14,7 \\
Cariñena & 14.809 & 31,3 \\
Campo de Borja & 4.429 & 9,4 \\
\hline Total has D.O. & 32.862 & 69,5 \\
\hline Demarcaciones geográficas Vinos de la Tierra & Hectáreas & \% del total has \\
\hline Bajo Aragón & 1.912 & 4,0 \\
Ribera Gállego_Cinco Villas & 222 & 0,5 \\
Ribera del Jiloca & 1.370 & 2,9 \\
Ribera del Queiles en Aragón & 48 & 0,1 \\
Valdejalón & 484 & 1,0 \\
Valle del Cinca & 518 & 1,1 \\
\hline Total Hectáreas V.T. & 4.554 & 9,6 \\
\hline Total superficie de viñedo & 47.299 & \\
\hline
\end{tabular}

Fuente: Anuario Estadístico de Aragón. 200; Revista Surcos. 2007.

Entre ellas destaca por su extensión la garnacha, especialmente en su variedad tinta, con la que se producen hoy algunos de los vinos con más personalidad de Aragón. En la década de los ochenta Albisu (1987) señala que esta variedad supone aproximadamente la mitad de la superficie del viñedo aragonés, alcanzando el 75\% en la provincia de Zaragoza y el 45\% en Teruel, mientras en Huesca tiene menor presencia, con un $9 \%$ de la superficie plantada, donde el arranque de viñas viejas, el abandono de parcelas tradicionales y la introducción de especies extranjeras en las zonas mejor orientadas, pone en peligro su existencia, como indica Casanova (2008; 17-18). A finales de la década del 2000, este mismo esquema se mantiene, con un 50,5\% de las plantaciones ocupado por garnachas en el conjunto de Aragón, siendo el 49,4\% de garnacha tinta, localizándose en su mayor parte en la provincia de Zaragoza.

Ocupan menos superficie otras autóctonas, además de las citadas en la tabla 3: moristel, crespiello o vidadillo, moscatel romano, provechón, parraleta, parrel o alcañón; en algunas fuentes se citan otras variedades que se han perdido o tienen escasísima presencia en los viñedos actuales (Casanova, 2008). De entre las citadas como principales, la variedad tempranillo es considerada por los expertos como autóctona española por la antigüedad de su cultivo, tratándose posiblemente de una variedad de la pinot noir 
Tabla 3. Variedades de uva en Aragón Principales variedades autóctonas (has)

\begin{tabular}{|l|r|}
\hline Uva blanca & 517 \\
\cline { 1 - 1 } Garnacha blanca & 5.930 \\
Macabeo (Viura) & 386 \\
Robal & 1.022 \\
Cariñena (Mazuela) & \\
\cline { 1 - 1 } Uva tinta & 24.047 \\
\cline { 1 - 1 } Garnacha tinta & 187 \\
Garnacha peluda & 6.998 \\
Tempranillo & \\
\cline { 1 - 1 } Principales variedades foráneas (has) & \\
\cline { 1 - 1 } Uva blanca & \\
\cline { 1 - 1 } Chardonnay & 4.172 \\
\cline { 1 - 1 } Uva tinta & 2.518 \\
\cline { 1 - 1 } Cabernet sauvignon & 2.396 \\
\hline Merlot & \\
\hline
\end{tabular}

Fuente: Departamento de Agricultura. DGA.

introducida en la Edad Media por los monjes de Cluny. Pero como se cultiva hoy en muchas zonas del mundo, no todas las fuentes la citan como autóctona en Aragón, aunque algunas de las Denominaciones de Origen sí la consideran de esta categoría. Entre las especies foráneas destacan por su extensión la cabernet sauvignon, seguidas de merlot y syrah y otras con menor extensión, como la pinot noir y la gewürztraminer.

Proteger la biodiversidad es una de las propuestas de la Convención Europea del Paisaje y es evidente, en este sentido, el interés de variedades de cepas tan antiguas. A nuestro juicio, no debe prevalecer exclusivamente el interés económico de unos mayores rendimientos. Las sucesivas OCM del vino han propiciado el arranque de las cepas más viejas, siendo ésta una de las razones del descenso general de la superficie de viñedo, ya que en 2005 casi el 20\% del total de las plantaciones aragonesas tenían más de 25 años. Pero la importancia de las viñas viejas es grande, por su valor histórico y ecológico, especialmente en el secano, que es la parte más importante del viñedo aragonés, donde esas viñas viejas constituyen el 45\% del total (tabla 4 y figura 3). 
Tabla 4. Distribución del viñedo aragonés según antigüedad de la plantación

\begin{tabular}{|l|c|c|c|c|c|c|}
\hline Años & has secano & \% secano & has regadio & \% regadio & Total viñedo & \% del total \\
\hline >35 & 8.700 & 23,3 & 499 & 4,3 & 9.199 & 18,8 \\
25 a 34 & 8.248 & 22,1 & 470 & 4,1 & 8.718 & 17,9 \\
24 a 15 & 6.991 & 18,7 & 665 & 5,8 & 7.656 & 15,7 \\
14 a 5 & 9.216 & 24,7 & 6.274 & 54,6 & 15.490 & 31,7 \\
$<5$ & 4.155 & 11,1 & 3.591 & 31,2 & 7.746 & 15,9 \\
\hline Totales & 37.310 & 100 & 11.499 & 100 & 48.809 & 100 \\
\hline
\end{tabular}

Fuente: DGA. Dep. Agricultura. Anuario de Estadística Agraria 2008-2009. Elaboración propia.

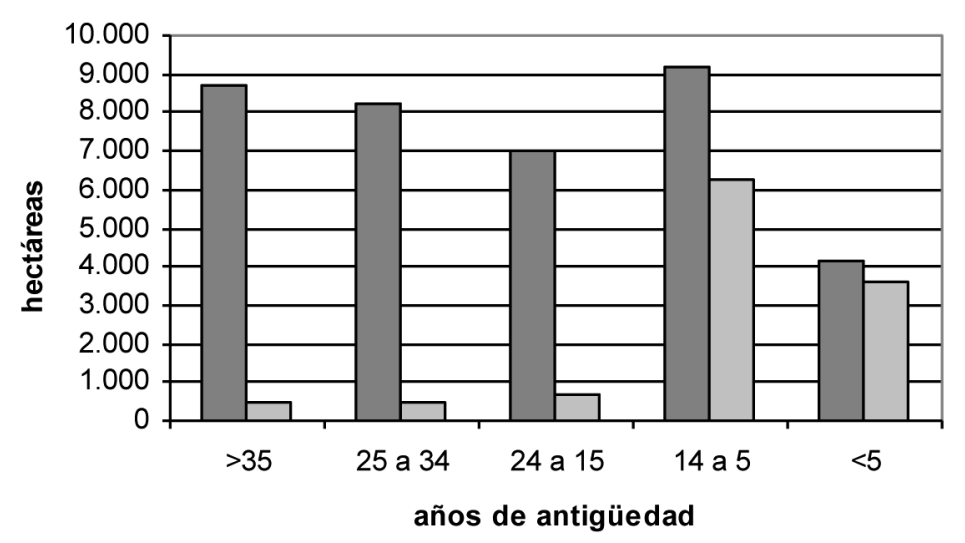

has secano $\square$ has regadío

Figura 3. Antigüedad del viñedo aragonés en secano y regadío.

Fuente: DGA. Dpto. Agricultura. Anuario de Estadística Agraria 2008-09. Elaboración propia.

Los viñedos más jóvenes están en el regadío, ya que hasta hace unos pocos años las vides no podían regarse. Las plantaciones nuevas coinciden, además, en buena parte con la expansión de las variedades más comerciales y el interés por competir en los mercados nacionales e internacionales, siempre ajustándose a las normas de los Consejos Reguladores de cada DO.

Desde la campaña 1974-75 y siguientes se puso de manifiesto un excedente de vino comunitario que supuso que una parte importante de la producción se orientase a la 
destilación como alcohol. Por ello se tomaron las primeras medidas que prohibían, entre otras actuaciones, nuevas plantaciones, incentivando los arranques y buscando la mejora de la calidad. Con los mismos principios se estructuró el plan 1980-86, cuyo objetivo era buscar un equilibrio entre la oferta y la demanda. El control de la producción tuvo un efecto limitado, pero, tal como plantea Albisu (1987:7), el arranque de viñas tuvo mayores repercusiones, superando la superficie programada, con el abandono sobre todo de las plantaciones marginales, menos productivas, que, en muchos casos, no han sido sustituidas por otros cultivos, lo que ha tenido efectos derivados, como la erosión de esas parcelas. Los sucesivos intentos de reestructurar el viñedo y controlar la producción de vino mantienen las mismas tendencias. La más reciente política de la UE al respecto, en conexión con las recientes reformas de la PAC y adoptada igualmente por Aragón, se plasma en la OCM de 2008 (Reglamento CE nº 479/2008). Su objetivo general es conseguir un sector vitivinícola sostenible, que a un tiempo sea competitivo, garantice el equilibrio entre la oferta y la demanda y proteja las mejores tradiciones vitivinícolas, potenciando a la vez el tejido social y protegiendo el medioambiente rural, sin hacer especial alusión al paisaje. Esta normativa se habría de desarrollar en varias etapas: la dos primeras abarcarían los años 2008 y 2009-2011 y en este periodo, a la vez que se limitan los derechos de plantación, se estimula el arranque de viñas; en las siguientes etapas, que deberían desarrollarse entre 2012 y 2019, se insiste en la reestructuración del viñedo, incluyendo el arranque de cepas, y alcanzando finalmente los objetivos propuestos al principio. Hay que añadir que a lo largo de toda esta etapa se incide, igualmente, en el desarrollo rural y los requisitos medioambientales.

No trataremos aquí de explicar más ampliamente las implicaciones del Reglamento, pero hay que insistir en que en el momento actual el riesgo de perder una buena parte de este paisaje cultural es evidente, máxime en los espacios rurales donde el envejecimiento de los jefes de explotación es constante y pueden entender las ayudas propuestas como un estímulo para la jubilación. En noviembre de 2008, cerca de 2.500 viticultores aragoneses habían solicitado subvenciones para el arranque de viñas, lo que suponía la desaparición de unas 5.500 ha de viñedo; el gobierno aragonés, consciente del problema, frenó parcialmente este abandono para la campaña 2008-2009 con otras líneas de ayuda, basadas tanto en el mantenimiento de la biodiversidad que suponía las viñas viejas como en la preservación del medio ambiente, al proteger determinadas zonas de la erosión, además de subvencionar la modernización de las explotaciones. En la campaña siguiente, 2009-2010 se mantuvo la misma política, de modo que casi un millar de agricultores solicitaron ayudas agroambientales para mantener unas 3.000 ha de las variedades tradicionales, la mayor parte garnachas viejas, pero también otras, como macabeo, vidadillo, bobal o cariñena. Estos viñedos se localizan en áreas de secano con pendiente igual o superior a un $4 \%$ y con gran riesgo de erosión, donde se cultivan viñas con más de 20 años de antigüedad (García, 2010). Las ayudas, integradas en el Plan de Desarrollo Rural, tienen carácter plurianual y cuentan con un presupuesto de seis millones de euros para el periodo 2010-2013, que se repartirán a razón de dos millones de euros por año. 


\section{Los viñedos en las denominaciones de origen aragonesas}

Como ya se ha expuesto, las áreas que destacan por la concentración de la superficie de viñedo son las que delimitan las Denominaciones de Origen Protegidas (DOP en adelante). Es en ellas donde se mantienen los paisajes más característicos y la vitivinicultura se ha convertido en motor de desarrollo.

\subsection{Algunas consideraciones generales sobre las Denominaciones de Origen Protegidas}

Las Denominaciones de Origen no son un hecho nuevo: a finales del siglo XIX Francia establece las primeras demarcaciones y en los primeros decenios del siglo XX se crearon en España para el sector del vino, con la aparición del Estatuto del Vino de 1932. A partir de 1970 se dictan nuevas normas (Ley 25/1970; Estatuto de la Viña, del Vino y de los Alcoholes (BOE de 5 de diciembre 1970); Ley 24/2003 de la Viña y del Vino, que recoge las DO). En el marco de la Unión Europea, la normativa para estas demarcaciones fue fijada en 1992, equiparándose las DO a la Protected Designations of Origin (PDO).

La estrategia que impulsó la creación de las zonas con DO vinícola tiene como punto de partida la fuerte competencia en el mercado mundial de los vinos desde hace varias décadas. En las demarcaciones que consiguen ese reconocimiento, la calidad del vino queda protegida por unos organismos reconocidos, los Consejos Reguladores, cuyas funciones son en España la inspección y asesoramiento a las bodegas (Ley 24/2003) y, a partir de diciembre de 2007, la función certificadora. Estos organismos cobran singular importancia porque aseguran para el consumidor un control de dicha calidad y su salubridad, actuando como herramienta de competitividad territorial, como señala Lorente (2001).

Ciertamente el concepto de "calidad" no está exento de una carga subjetiva. La RAE lo define como "el conjunto de propiedades inherentes a una cosa que permite apreciarla como igual, mayor que las restantes de su categoría" o bien, como señala Manfield (2003: 10), "quality seems to be at once defined by the physical characteristics of the product and also by changing socio-spatial relations". Pero en términos comerciales hace referencia a la percepción que tienen los consumidores sobre la capacidad de un producto para satisfacer sus necesidades, considerando la superioridad del producto frente a otros (Rubio, 2012; Cambra y Villafuerte, 2009). Puede afirmarse que la estrategia de las empresas de las DOP se encaminan en este sentido. En suma, en este artículo subyace el concepto de que la calidad es, como indica Climent (2012), "un valor que da a los productos la capacidad para competir en el mercado", pudiendo referirse a los obtenidos mediante un proceso estándar, conocido y controlado, o los 
diferenciados, con características propias pero cuyo proceso de producción está igualmente sometido a controles y normas.

La vinculación del producto al lugar es también útil para re-localizar los sistemas de producción agroalimentaria (Ilbery, 2001). La expresión Denominación de Origen no sólo hace referencia a un territorio bajo cuyo nombre se designa y protege un producto agrícola originario, sino que evoca también a los grupos humanos que han sido capaces de crear un producto reconocido por su calidad y por unas características diferentes y singulares, que se deben a las condiciones naturales del medio geográfico en el que se elabora, a la introducción de nuevas tecnologías y a la existencia de un capital humano competente; es, por tanto, una seña de identidad cultural (Barco et al., 2006).

Por todo ello, contar con una DOP que avale una producción local es el objetivo de muchos agentes económicos y sociales en variados ámbitos rurales, ya que permite mantener unas tradiciones, unas esencias culturales determinadas, y fomentar a un tiempo la innovación, desarrollando, como en el caso e la vid, una agroindustria que tiene por objeto la comercialización del producto, extendiendo también con él el conocimiento de un territorio determinado al que se asocia. La existencia de una DOP favorece igualmente otras actividades, como el turismo, lo que permite fijar población y crear riqueza económica. En suma, las DOs son uno de los motores fundamentales del desarrollo económico y social de los territorios donde se han implantado (Loscertales, 2009).

\subsection{Las características de las áreas vitivinícolas aragonesas con Denominación de Origen}

Actualmente existen cuatro DOP vitícolas en Aragón, localizadas en espacios donde tradicionalmente se había cultivado el viñedo (Sánchez. y Gil, 1997). La iniciativa de las Cooperativas de viticultores, que ya existían, ha sido fundamental en la génesis de estas DOs, poniendo de relieve el papel del capital social, el arraigo en una zona determinada y el mantenimiento de una herencia cultural en relación con el cultivo de la vid, su paisaje y la elaboración del vino.

El medio físico en el que se localizan tiene las condiciones ecológicas aptas para la vid y entre las cuatro DOP hay similitudes y también algunas diferencias. Tres de esas DOP ocupan zonas de piedemonte, sea en el Pirineo (Somontano de Barbastro) o en la Cordillera Ibérica (Cariñena, Campo de Borja), mientras la cuarta, Calatayud, se instala en las laderas bajas y pequeños glacis y conos de deyección del valle medio del Jalón. Los suelos son pedregosos, con predominio de los pardo-calizos y xero-cálcicos, sobre glacis y terrazas, bien aireados y permeables Loscertales, 2009; Lete Vela, 1998). El clima es de tipo mesomediterráneo-continental cálido, con precipitaciones medias en torno a los 400-600 mm anuales, veranos con largos periodos secos interrumpidos por tormentas que proporcionan lluvias importantes, primaveras y otoños más húmedos e 
inviernos con escasas precipitaciones, rara vez en forma de nieve; el número de días de lluvia al año es reducido (70-80) y en todas las DOs se reciben más de 2.500 horas de sol. Las temperaturas medias entre los $12^{\circ}$ en los terrazgos situados a mayor altitud y los $14^{\circ}$ de los más llanos y soleados; los veranos son templado-cálidos, con medias de $22^{\circ}-24^{\circ}$, no exentos de episodios muy cálidos, y los inviernos frescos, cuyas temperaturas pueden variar, según la altitud, entre los $7^{\circ}$ y los $3^{\circ}$, con heladas frecuentes que pueden prolongarse hasta la primavera. La amplitud térmica entre las mínimas y las máximas absolutas está en torno a 28-30 (Cuadrat, 1999; López Martín et al. 2007).

Las dos primeras Denominaciones de Origen en obtener el reconocimiento se ubican en el piedemonte de las Sierras Ibérica. La DO Cariñena, que es la más extensa y debe su reconocimiento a la mezcla de tradición y modernidad, fue fundada el 8 de septiembre de 1932 y adaptada más tarde a los requisitos actuales, ocupando por su antigüedad el segundo lugar en España, después de la de Rioja. La DO Campo de Borja se fundó algo más tarde, en 1980, pero históricamente puede compararse a Cariñena en tradición y extensión, (García Manrique, 1960), promocionando actualmente su territorio como El Imperio de la Garnacha, variedad autóctona en la que basa su estrategia de calidad (http://www.campodeborja.com/vinos.htm). La DO Somontano, que se localiza en las estribaciones pirenaicas próximas a la localidad de Barbastro, donde el viñedo existía desde antiguo, se fraguó en los años 1960 con la creación de una cooperativa comarcal del vino que aunaba a los tradicionales viticultores, pero no solicitó su calificación hasta 1974, siendo aprobada en 1984; Su extensión es reducida y su expansión, reciente, pero es una de las zonas más dinámicas y también la que ha introducido más especies foráneas, lo que no siempre ha sido bien valorada por los habitantes de la comarca, pero que actualmente intenta introducir de nuevo variedades autóctonas (Bielza et al., 2006). La DO Calatayud, localizada en las tierras vitícolas del valle medio del río Jalón, es la de más reciente reconocimiento, ya que nació en 1989, pero tiene un futuro prometedor, apoyado en un plan estratégico de calidad del producto, con una orientación muy selecta y la búsqueda de nichos de mercado en consonancia (CAI, 2006).

Estas cuatro DOs agrupan algo más del 70\% de los viñedos aragoneses, pero tienen diverso impacto en el paisaje regional, puesto que abarcan un número de municipios, una superficie de viñedo y un número de viticultores desigual. Calatayud y Somontano adscriben un elevado número de términos municipales, generalmente de reducido tamaño, con zonas de regadío en las que la vid no se ha mantenido y espacios de secano más adecuados para otros cultivos (figura 1, tabla 5); en ellos el viñedo se halla más disperso y solamente en algunas áreas ocupa espacios significativos, de tal forma que sobre el total de tierras cultivadas el porcentaje de las viñas es escaso, especialmente en el Somontano. Sin embargo en Cariñena y Campo de Borja el impacto paisajístico es mucho mayor, con una cuarta parte de las tierras, aproximadamente, ocupadas por las vides e incluso con municipios donde se da cuasi monocultivo de la vid. Puede añadirse que en el caso del Somontano, el área de viñas controladas por DOP supera los límites de la demarcación administrativa comarcal (Loscertales, 2009: 34-37). 
Tabla 5. Las Denominaciones de Origen vitícolas aragonesas

\begin{tabular}{|l|c|r|r|r|r|}
\hline \multirow{2}{*}{$\begin{array}{l}\text { Denominaciones } \\
\text { de Origen }\end{array}$} & \multirow{2}{*}{$\begin{array}{c}\text { Municipios } \\
\text { adscritos }\end{array}$} & \multicolumn{3}{|c|}{ Superficie (has) } & \multirow{2}{*}{$\begin{array}{c}\text { \% sobre total } \\
\text { tierras cultivadas }\end{array}$} \\
\cline { 3 - 5 } & 43 & 6.166 & 521 & 6.687 & 13,5 \\
\hline Calatayud & 16 & 4.854 & 2.081 & 6.935 & 20,9 \\
Campo de Borja & 14 & 10.829 & 3.980 & 14.809 & 29,6 \\
Cariñena & 43 & 2.964 & 1.465 & 4.429 & 3,1 \\
Somontano & & & Regadio & Total & \\
\hline
\end{tabular}

Fuente: D.G.A. Dep. Agricultura: Cuestionarios 1T. Consejos Reguladores D.O. 2007/08. Elaboración propia.

Después de un periodo de reducción drástica de la superficie de viñedo, debido en buena medida a los ajustes estructurales establecidos por la Unión Europea en las OCM del vino, en el último decenio las demarcaciones con Denominación de Origen han ido incrementando el espacio cultivado hasta un $25 \%$ en el conjunto, siendo el Somontano la DOP de mayor expansión (figura 4).

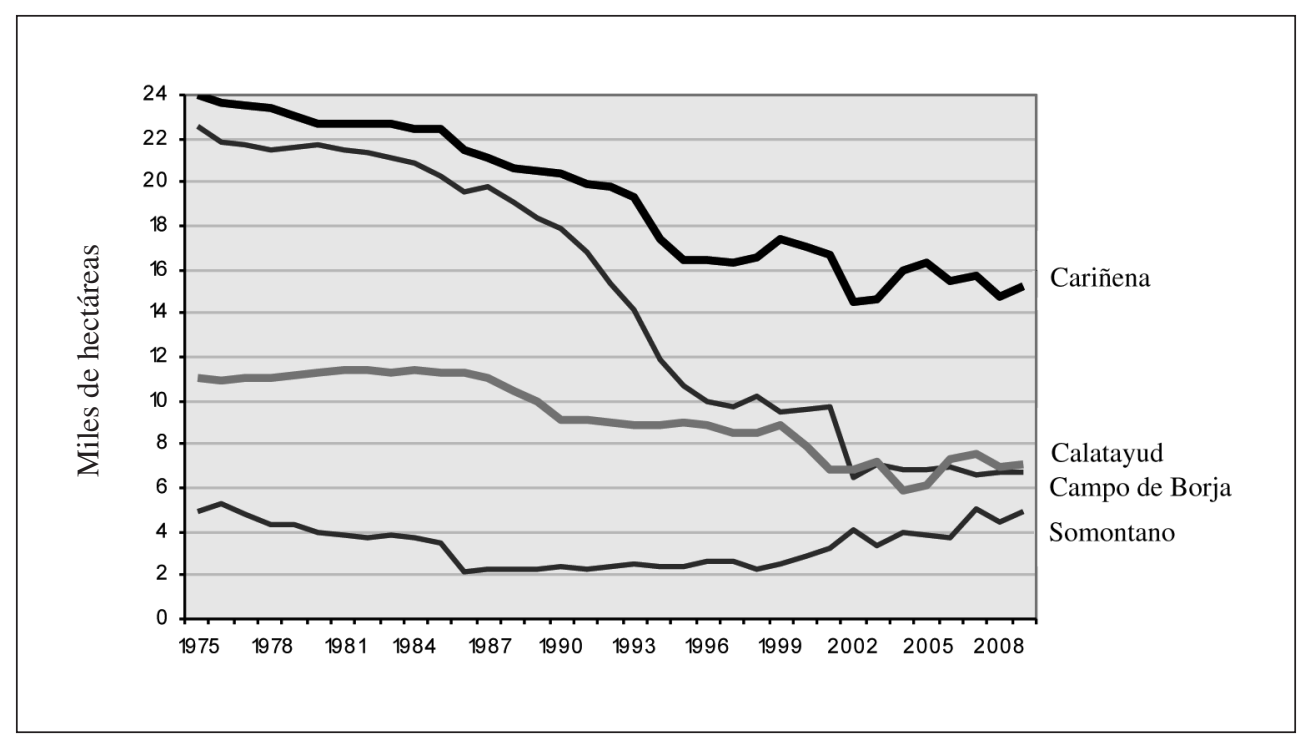

Figura 4. Evolución de la superficie de viñedo en las zonas DO.

Fuente: Cuestionarios 1T. Gobierno de Aragón. Elaboración propia. 
Este paisaje, pese a su base tradicional, no es estático, pues ha sufrido diversas modificaciones al incorporar novedades técnicas, como el cambio de método de plantación del vaso a la espaldera o la introducción de variedades de uva foráneas, ya aludido, aunque sigan predominando en tres de las DOs las variedades tradicionales y todas ellas estén especialmente interesadas en la recuperación de esas cepas autóctonas, para resaltar las propiedades únicas de sus vinos y mantener tanto la biodiversidad como el arraigo cultural (Lorente y Barbacil, 2004). En la tabla 6 se indican el porcentaje que suponen las especies autóctonas en cada una de ellas, respecto de la superficie total de viñedo, quedando de manifiesto su importancia y el interés patrimonial y agrobiológico de mantenerlas.

Tabla 6. Importancia de las variedades de viña autóctonas en las D.O.

\begin{tabular}{|l|c|c|c|c|}
\hline D.O. Protegidas & Cariñena & C. Borja & Somontano & Calatayud \\
\hline \% viñas autóctonas & 52,57 & 62,57 & 27,49 & 91,27 \\
\hline
\end{tabular}

Fuente: DGA y Reglamentos de constitución de las DO.

De todas las variedades citadas más arriba para el conjunto de Aragón, en las Denominaciones de Origen también es la garnacha tinta la que ocupa mayor extensión: un $61 \%$ de la superficie total del viñedo de Calatayud, un 59\% del de Borja y un 33\% del de Cariñena, siendo, en cambio, solamente un $6 \%$ en el Somontano, en donde, sin embargo, como sucede en la marca Secastilla, es la materia prima para unos vinos de gran calidad. La DO Cariñena dedica, además, una parte significativa de sus tierras a la variedad macabeo (el 15\%) y es la única que mantiene las cepas de cariñena o mazuelo, original de estos pagos, con cierta importancia (5\%). Las cepas de Tempranillo ocupan extensiones considerables en las cuatro zonas, pero solamente las consideran tradicionales o autóctonas Somontano y Calatayud.

En cuanto a las innovaciones recientes, la que tiene una mayor expresión paisajística es el cultivo en espaldera, que ocupa más del 40\% de la superficie vitícola de las denominaciones de origen, habiéndose adoptado este sistema de plantación por motivos económicos, como el mayor rendimiento y fácil recolección mecanizada, y ecológicos, por ofrecer a las plantas una mayor insolación (Tabla 7). No obstante, el porcentaje de viñedos en los que se ha adoptado este método es desigual entre las DOP, siendo en Somontano donde se ha generalizado de manera más clara -quizá porque es la más joven y de expansión más reciente, con introducción de variedades foráneas orientadas a un mercado estándar- y en Calatayud sonde se ha adoptado en menor medida esta modalidad de cultivo, posiblemente porque una parte importante de sus viñedos están en espacios de fuerte pendiente y difícil acceso, por cuya razón muchas de las tareas de cultivo se realizan a mano. 
En suma, las áreas con denominación de origen han mantenido el paisaje cultural de los viñedos y las cepas tradicionales, pese a las innovaciones introducidas, que han originado su sustitución parcial o cambios en el método de plantación de nuevas cepas. Así, pese al retroceso del viñedo en el resto de la región, la territorialización de la producción de vino al conferirles una indicación geográfica ha sentado las bases de un desarrollo rural endógeno.

Tabla 7. Nuevos métodos de plantación

\begin{tabular}{|l|c|c|}
\hline D.O. & has en espaldera & \% sobre viñedo \\
\hline Calatayud & 922,24 & 13,8 \\
Campo de Borja & $3.575,52$ & 51,6 \\
Cariñena & $6.315,31$ & 42,6 \\
Somontano & $3.498,32$ & 79,0 \\
\hline
\end{tabular}

Fuente: DGA. Depatamento de Agricultura. Elaboración propia.

\section{Cultura vitivinícola y desarrollo rural endógeno}

La larga historia del cultivo de la vid en las tierras aragonesas y la continuada tradición de su transformación, conforman una cultura específica que, como se ha dicho, tiene su expresión en el paisaje, pero además es un claro ejemplo de desarrollo endógeno, al ubicar in situ una industria que utiliza materia prima local y también capital y fuerza de trabajo, al menos en sus inicios y todavía hoy en bastante proporción, aportando cierta estabilidad a las rentas locales y conectando con el exterior mediante la innovación y la exportación.

\subsection{Vinos y bodegas en las Denominaciones de Origen}

Frente a la reducción general del espacio vitícola, se constata, en cambio, que la producción de vino de calidad se ha incrementado considerablemente (figura 5), si entendemos ese concepto de calidad como la confianza del consumidor en los controles que aseguran los Consejos Reguladores. El incremento se ha dado, obviamente, en las áreas con Denominación de Origen y Vinos de la Tierra, constituyendo hoy la vitivinicultura una importante base económica para los habitantes de esas comarcas y formando parte del su paisaje las bodegas y los museos del vino.

Actualmente se producen en Aragón algo más de un millón de hectolitros de vino, entre los blancos, rosados y tintos, predominando el último, lo que es fácilmente de- 
ducible del predominio de la garnacha tinta citado. Desde finales de los años noventa hasta el momento actual, pese a los problemas de reestructuración del viñedo y la fuerte competencia en el mercado nacional e internacional, esa producción se ha incrementado un 100\%, creciendo especialmente los blancos embotellados, en busca de nichos de mercado adecuados (Castelló et al., 2010).

De la cantidad de vino citada, el $90 \%$ es producido por las DO, elaborado en más de sus cien bodegas, que son la mayor parte de las regionales (Tabla 8). Entre ellas, las Cooperativas, a cuyo papel en la génesis de las DO se aludió más arriba, suman 24, lo que supone una cuarta parte, aproximadamente, del total de las existentes en estos territorios. Pero su papel es mucho más importante que su número, ya que están claramente enraizadas a la cultura local y su identidad forma parte de ella. Además generalmente ocupan el primer lugar por su producción. Colaboran ampliamente, por tanto, al desarrollo endógeno.

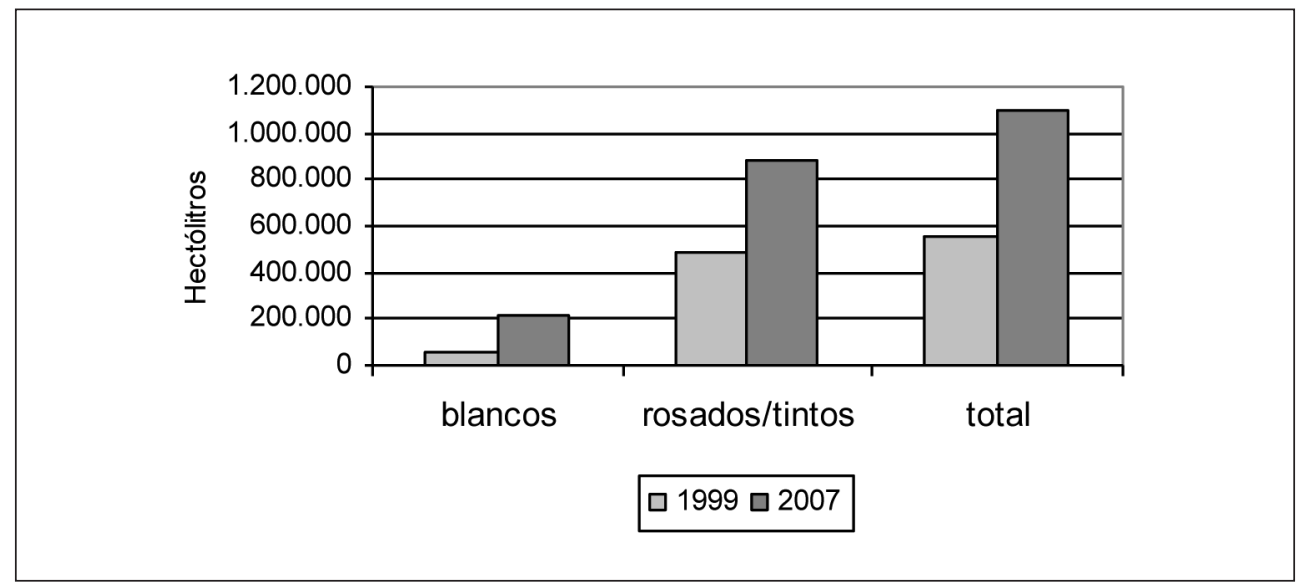

Figura 5. Evolución de la producción de vino en Aragón. 1999-2008.

Fuente: Anuarios de Estadística Agraria. Gobierno de Aragón. Elaboración propia.

Las bodegas y su arquitectura forman, también, parte integrante del paisaje actual de los viñedos, subrayando su identidad y aunando tradición y modernidad en estos territorios. Los edificios que albergan las bodegas han sufrido modificaciones, en algunos casos por la remodelación de las ya existentes, pero especialmente por la construcción de otros nuevos, que destacan por su diseño y singularidad, sumando, además, un patrimonio artístico interesante, como señalan para Cariñena Almazán et al. (2007) o Marías (2005), pero queda patente también en el Somontano y, en menor medida, en las otras demarcaciones con DOP. 
Sin duda, el aspecto externo de esas industrias ha cambiado mucho en Aragón, igual que en otras partes de España, y tanto su fisonomía como las técnicas utilizadas en el proceso de elaboración del vino distan mucho del que tenían las bodegas excavadas en las colinas y cerros y los lagares tradicionales, donde los caldos se obtenían con el pisado de la uva. En el proceso de producción de las actuales bodegas, construidas con modernas normas arquitectónicas, hay un cambio técnico y una innovación muy importantes, que también ha afectado al paisaje, integrándose en él. Pero hay que señalar que en muchas de las zonas vitívinícolas todavía se conservan aquellas bodegas primeras, que son muestra de una arquitectura rural funcional, como señala Marías (2005), especialmente visibles en Cariñena y Campo de Borja, así como en otras comarcas de Aragón, donde la vitivinicultura fue importante, como la de Tarazona y el Moncayo, y que proliferan igualmente en Castilla y León. Ciertamente, el uso actual ha cambiado, orientándose al turismo o al uso familiar solamente, pero mantienen su impronta en el paisaje, confirmando la larga historia de esta actividad económica agraria y agroindustrial en tierras aragonesas. Cuando la industrialización alcanza la elaboración del vino, que debe acceder a un mercado más amplio para que el cultivo del viñedo no sea abandonado, las bodegas se modernizan, edificando, primero, instalaciones exentas de los tradicionales lagares subterráneos con una estética de nave industrial y, más recientemente, edificios modernos de atractiva arquitectura.

En cuanto a las técnicas, las DOP aragonesas han realizado grandes inversiones en sus bodegas, encaminadas a tecnificar sus instalaciones, adquiriendo bienes de equipo avanzados y ajustándose a los cambios con sucesivas remodelaciones y ampliaciones, incorporando además enólogos o químicos que velen por un proceso adecuado en la elaboración de los caldos. El objetivo ha sido adaptar la producción a los cánones de calidad, entendidos como la confianza de los consumidores en la seguridad que ofrecen los reglamentos de esas DOP en el marco de un mercado global y de la competencia de nuevos países, teniendo presentes los principios de sostenibilidad ambiental (Escalona et al., 2010). Así, con una base ineludible de convenciones domésticas, ya que parte de ese mercado se apoya en la tradición, las variedades autóctonas y el arraigo, en el momento actual puede afirmarse que la industria vitivinícola aragonesa de las DOP consagra un cambio hacia las convenciones y los mundos de producción industrial y comercial, si aceptamos las teorías sobre la evolución de las actividades industriales (Lindkvist y Sánchez, 2007), a lo que se aludió en la introducción, en un marco en el que los productores toman sus decisiones, atendiendo a los gustos de los consumidores, en función de una mejora de la rentabilidad, de la calidad y de una expansión de sus ventas.

En las DOP de más reciente expansión, como Somontano, forman ya parte del paisaje las construcciones del tipo chateau francés, en el que la bodega se integra a la perfección con los viñedos que la rodean. Este patrimonio arquitectónico industrial es también un importante recurso turístico y uno de los pilares clave para el desarrollo rural, especialmente en las zonas con Denominación de Origen, en las que el enoturismo es 
Tabla 8. Producción de vino en las DOP aragonesas

\begin{tabular}{|l|c|c|c|}
\hline DOP & $n^{\circ}$ Bodegas D.O. & Producción* & Prod. media por bodega \\
\hline Calatayud & 14 & 10,3 & 0,74 \\
Campo de Borja & 17 & 24,3 & 1,43 \\
Cariñena & 51 & 64,6 & 1,27 \\
Somontano & 32 & 14,4 & 0,45 \\
\hline
\end{tabular}

* Producción total media 2007-08-09 en millones de litros.

Fuente: DGA. Departamento de Agricultura.

importante. Muchas de las bodegas realizan catas, visitas guiadas y otras actividades que se han integrado en su estrategia económica. A ello se suma el acondicionamiento como lugares de ocio de algunas de las bodegas tradicionales excavadas en la roca, a lo que se ha hecho referencia, los museos del vino y la vid existentes en Cariñena, Somontano y el Campo de Borja -éste último integrado en el Monasterio de Veruela, una obra del siglo VXII-, así como la gastronomía asociada, todo lo cual constituye un atractivo indudable que ha permitido trazar rutas turísticas específicas, oficialmente confirmadas, como la de Somontano, o en vías de serlo, como en el Campo de Borja, además de otras señaladas por la propia Comunidad Autónoma (Frutos et al., 2008).

Es posible afirmar, por lo tanto, que la economía local que se asienta en estos paisajes y de la que ellos mismos son expresión, utiliza fundamentalmente los recursos locales y por tanto, propicia un desarrollo endógeno y sostenible, en el que no están exentas las innovaciones.

\subsection{La participación en los mercados}

Es cierto que los vinos deben su singularidad al territorio que les da origen, pero precisamente por esta íntima relación con él son sus mejores embajadores en el exterior. Es la conexión con el mercado la que permite tanto el conocimiento de estos territorios como el mantenimiento de la actividad y las economías locales. Las DO aragonesas han logrado abrirse camino en un mercado tan competitivo como es el de este producto, no solo en el nacional, sino en el extranjero.

Los técnicos bien preparados -enólogos, ingenieros, comerciales y publicistas, entre otros- aportan nuevas prácticas que son fundamentales, tanto para alcanzar la calidad deseada como para difundir sus cualidades en el mercado. En suma, en estos ámbitos en los que la tradición ha sido la base para el mantenimiento del cultivo y su elaboración, se asiste a una nueva cultura de gestión, con cotas de profesionalización muy altas (Los- 
Tabla 9. La relación de las D.O. con el mercado

\begin{tabular}{|l|r|r|c|c|}
\hline D.O./mercados $(\mathrm{Hl})$ & Interior & Exterior & Total vendido & \% sobre producción $n^{*}$ \\
\hline Calatayud & 7.122 & 35.800 & 42.922 & 41,5 \\
Campo de Borja & 44.618 & 92.822 & 137.440 & 56,5 \\
Cariñena & 134.604 & 249.883 & 384.487 & 59,4 \\
Somontano & 44.618 & 92.822 & 137.440 & 95,5 \\
\hline
\end{tabular}

* \% indicativo, obtenido sobre producción media de 2007-09. Elaboración propia.

Fuente: DGA. Departamento de Agricultura. 2009.

certales, 2009). La evolución de este mercado es positiva en todas las DO, tanto en el ámbito nacional como en el internacional. En conjunto, las ventas de la campaña 2008-09 superan en Calatayud el 40\% de la producción media de vino del trienio citado, el 50\% en Cariñena y Campo de Borja y el 90 en Somontano (tabla 9), entendiendo estos valores como indicativos solamente, cifras que se siguen incrementando en las campañas siguientes a pesar de la crisis económica global. El resto de la producción forma parte del stock de vinos de crianza o reserva o tiene un mercado local. Aunque la introducción en el mercado no es igual para las cuatro zonas, todas ellas tienen entre sus prioridades la expansión y su estrategia se orienta a aumentar sus ventas y buscar nuevos nicho de mercado, sea por seducción, con vinos de los llamados "de autor" o con selecciones y combinaciones especiales propias de esta tierra, sea por innovación. Para ello se están haciendo inversiones importantes para promocionar los vinos aragoneses en los cinco continentes, al amparo de las subvenciones que recoge la última OMC que insta a fomentar la difusión de los caldos europeos en países no comunitarios, tal como señala Martínez (2010). En todo caso los precios que a los que se ofrecen los vinos aragoneses juegan un papel complementario en la búsqueda de mercados, pero no fundamental.

Sin duda un alto porcentaje de la producción que se vende lo hace con precios bajos o medios de entre uno y cinco euros por botella, precios que son asequibles, y solo un segmento de esos vinos superan los precios altos, de más de 20 o $50 €$, e incluso los 100 en determinadas botellas de reserva (Guía Peñín 2009-2010; Guía Campsa, 20092010). Si se consideran las calificaciones estándar de los expertos respecto esos precios según las marcas, relacionados con la calidad, los resultados pueden verse en la tabla 10, donde los grados más altos, Ultra Premium e Icono, se adjudican a tres marcas, dos en Somontano y uno en Campo de Borja.

Las rentas directas que ingresan las bodegas de las DO superan en 2008, según la información disponibles en el ministerio de Medio Ambiente, Medio Rural y Marino, los cien millones de euros, siendo la cantidad mayor la de Somontano, pero estando muy próximas las de Cariñena y Campo de Borja. La renta más modesta de Calatayud 
Tabla 10. Categorías según precios unitarios por botella

\begin{tabular}{|l|c|r|r|r|r|r|r|r|}
\hline DOP & No marcas & 1 & 2 & 3 & 4 & 5 & 6 & 7 \\
\hline Calatayud & 63 & 28 & 16 & 9 & 7 & 3 & 0 & 0 \\
Campo de Borja & 61 & 16 & 14 & 8 & 14 & 8 & 1 & 0 \\
Cariñena & 144 & 44 & 32 & 29 & 32 & 7 & 0 & 0 \\
Somontano & 187 & 8 & 33 & 41 & 59 & 24 & 1 & 1 \\
\hline Total & 435 & 98 & 95 & 87 & 112 & 42 & 2 & 1 \\
\hline
\end{tabular}

Fuente: Anuario El Pais 2010 y aplicación de la clasificación estándar. Elaboración propia.

Categorías: 1: Básic (1-3 €); 2: Popular Premium (3-5€); 3: Premium (5-7 €); 4: Super Premium (7-14 €); 5: Ultra Premium I (14-75 €); 6: Ultra Premium II (75-150€); 7 : Icono (>150).

responde la juventud de esta DO y la menor extensión de sus viñedos, pero sin embargo es la que exporta al extranjero un porcentaje más alto de su producción.

Estos datos confirman la importancia de la industria vitivinícola a escala local y el papel en su desarrollo de las Denominación de Origen Protegida, cuyos paisajes son fruto de una larga historia y del saber hacer de los habitantes de estas comarcas, en cuya idea se ha venido insistiendo a lo largo de estas páginas.

\subsection{Población, trabajo y renta}

El interés social de los paisajes vitivinícolas radica también en el mantenimiento de una población agraria adscrita a los núcleos rurales y en el número de empleos que pueden generar tanto el cultivo como la transformación del producto. En 2006 las Denominaciones de Origen agrupaban a 9.293 viticultores, con un reparto desigual en las cuatro existentes (tabla 11) en relación con la importancia de la superficie cultivada y la orientación más o menos especializada de las tierras en cada una de las demarcaciones. Pero, en todo caso, es un significativo porcentaje de la población activa dedicada a la agricultura en estas zonas, con la gran ventaja de que el tipo de cultivo supone que muchos de los viticultores residan en estos municipios. Habría que añadir la oferta de trabajo estacional en los momentos de recolección, variable de unas campañas a otras, pero en todo caso importante.

En cuanto a la producción, el número de personas directamente ocupadas ha evolucionado positivamente, pese a la elevada automatización del proceso, que implica que casi un 75\% de las empresas tengan menos de 10 asalariados y solo un $15 \%$ más de veinte. Según los últimos datos publicados, en 2006 se censaban algo más de mil trabajadores (CAI, 2006; DGA, 2008). 
Tabla 11. Viticultores en las D.O.

\begin{tabular}{|l|c|c|}
\hline D.O. & Viticultores & Tamaño medio expl. \\
\hline Calatayud & 2.700 & 2,48 \\
Campo de Borja & 2.100 & 3,30 \\
Cariñena & 3.974 & 3,59 \\
Somontano & 519 & 5,29 \\
\hline Total & 9.293 & 3,30 \\
\hline
\end{tabular}

Fuente: Consejos Reguladores. Datos de 2006.

De modo indirecto también la oferta de servicios se beneficia de la actividad y las rentas de la zona sea por la atracción turística, sea por la necesidad de desarrollar el comercio, de realizar gestiones y operaciones financieras o suministros diversos y reparación de maquinaria.

La positiva repercusión demográfica de esta actividad puede parecer poco espectacular, pero si se parte de la base del impacto que ha tenido en todas las zonas rurales aragonesas la emigración selectiva y el consiguiente envejecimiento de la población, especialmente tras la crisis de la agricultura tradicional y la transformación de la economía española en los años sesenta del pasado siglo, es interesante analizar la situación, tomando como ejemplo las dos zonas en las que el viñedo es la base esencial de su economía, Cariñena y Campo de Borja, y comparando los datos con los de otras comarcas que tengan igualmente especialización agrícola, como Los Monegros, orientada a cultivos herbáceos con importante superficie de regadío, y Jiloca, donde se combinan los herbáceos y algunas superficies de viñedo, pero cuya fundamental vocación es pecuaria. Se han incluido también las cabeceras comarcales y aunque las diferencias no son demasiado llamativas, pueden considerarse suficientemente ilustrativas en relación con el tema que nos ocupa y permite considerar que estas demarcaciones vitivinícolas tienen algunos puntos positivos frente a esas otras orientaciones productivas agropecuarias y a la tónica general de las zonas rurales aragonesas (tabla 12) y aunque la población está muy envejecida, incluso por encima del índice medio de Aragón (19,6\%), ya de por sí bastante elevado, puede apreciarse que éste es algo más bajo en Cariñena y Borja que en las otras dos comarcas, especialmente en las cabeceras comarcales citadas.

Si se analizan otros datos referidos a la población activa y a la renta per cápita hay, igualmente, algunas diferencias (tabla 13). Aunque en las cuatro comarcas seleccionadas el peso de la población activa agraria es similar, con un valor un poco mas alto en Los Monegros, en las comarcas vitícolas los activos censados en industria son proporcionalmente más numerosos, lo que da fe de la importancia de las empresas vinícolas, a las que se suman otras complementarias. Algo similar ocurre con la renta per ca- 
Tabla 12. Evolución demográfica 1991-2009

\begin{tabular}{|l|r|r|c|}
\hline Comarcas/municipios & 1991 & 2009 & Índice vejez \\
\hline Campo de Cariñena & 10.173 & 11.214 & $24,0 \%$ \\
Cariñena municipio & 2.877 & 3.665 & $18,0 \%$ \\
Campo de Borja & 14.632 & 15.621 & $22,8 \%$ \\
Borja municipio & 4.060 & 5.030 & $17,8 \%$ \\
Los Monegros & 23.253 & 21.230 & $27,2 \%$ \\
Sariñena & 4.227 & 4.455 & $19,8 \%$ \\
Jiloca & 15.640 & 14.442 & $29,7 \%$ \\
Calamocha & 4.276 & 4.776 & $20,2 \%$ \\
\hline
\end{tabular}

Fuente: Instituto Aragonés de estadística. Elaboración propia.

Tabla 13. Reparto sectorial de la población activa y renta per capita. 2009

\begin{tabular}{|l|c|c|c|c|c|}
\hline Comarcas & Agricultura & Industria & Construcción & Servicios & Renta p.c.€ \\
\hline Campo de Cariñena & 6,8 & 28,9 & 17,1 & 41,2 & 12.794 \\
Campo de Borja & 7,8 & 30,5 & 15,3 & 42,9 & 12.890 \\
Los Monegros & 9,9 & 14,9 & 23,8 & 46,4 & 12.705 \\
Jiloca & 7,5 & 27,2 & 18,5 & 41,7 & 12.553 \\
\hline
\end{tabular}

Fuente: Instituto aragonés de estadística. Datos en porcentaje. Elaboración propia.

pita, que si bien en todas ellas es inferior a la media aragonesa, situada en 15.474 euros en 2009, en las zonas vitícolas es algo más elevada.

Por todo ello parece razonable preservar estos paisajes, base de la identidad y el desarrollo local endógeno y, a la vez, protectores del medio ambiente natural, cumpliendo así lo que propone la Convención Europea del Paisaje.

\section{Conclusiones}

A la luz de los datos que se exponen, se puede concluir afirmando, en primer lugar, que los paisajes de las DOP vitivinícolas aragonesas cumplen los requisitos para poder ser considerados patrimonio cultural, apoyándose en las razones siguientes: 
Por su innegable origen histórico, identificándose en muchos documentos el cultivo y las variedades de uva que hoy todavía se conservan, así como su transformación en vino en bodegas propias. Por tanto, esos paisajes están fuertemente arraigados en el territorio, formando parte de la cultura tradicional de sus habitantes y de sus señas de identidad.

Queda patente, igualmente, que aunque las condiciones naturales de la mayor parte de Aragón son adecuadas para mantener algunas hectáreas de viñedo, formando parte de la característica trilogía de los espacios mediterráneos, se ha constatado el descenso de la superficie dedicada a las viñas en el conjunto regional y su concentración en esas áreas que tienen la calificación de Denominaciones de Origen Protegidas, En ellas se reconoce ese paisaje cultural, con mayor o menor ocupación del espacio, y se identifican las variedades históricas de uva, siendo en estos espacios donde se ha mantenido el cultivo con mayor extensión, como herencia de una larga tradición, avalada por el papel de las Cooperativas en la génesis de estas demarcaciones, pero con un dinamismo que implica innovaciones y cambios en los métodos de cultivo y en las instalaciones para su elaboración.

En cuanto a su papel en el desarrollo local, la transformación de la materia prima in situ por las bodegas allí establecidas - de las cuales una cuarta parte son Cooperativas-, han permitido asentar población y renta y dar a conocer las distintas comarcas dentro y fuera de España. Estas empresas buscan en sus vinos tanto la calidad como la expansión de su venta en el mercado, todo ello apoyado en la incorporación de expertos en enología, introducción de nuevas técnicas de producción y crianza, lo que no obsta para apostar por el mantenimiento de la identidad territorial y las cepas autóctonas, además de incorporar otras foráneas de alto rendimiento y buena acogida entre los consumidores, todo ello complementado con estrategias comerciales para ampliar su mercado. En suma, según la teoría de las convenciones y los mundos de producción, se trata de una industria que, sin descartar la base doméstica de arraigo en el territorio, que le da singularidad, prima las convenciones industrial y comercial para poder adaptarse a un mercado cada vez más competitivo.

Pero es, precisamente, la globalización de esos mercados y la expansión a nivel mundial de los viñedos la amenaza que se cierne sobre estos paisajes, reflejada en las recientes políticas europeas y las OCM del vino. Por ello creemos importante la protección de este cultivo y su industria, como sostenibilidad de un patrimonio rural y del medio ambiente y como motor de desarrollo rural.

\section{Agradecimientos}

Este trabajo forma parte del proyecto de investigación CSO2008-05793-C03-02, financiado por el Ministerio de Ciencia e Innovación. 


\section{Bibliografía}

Albisu, L.M. (1998) La economía agroalimentaria en Aragón. Zaragoza, Colección CAI 100.

Almazán, D., Biel, P. y Vázquez, M. (2007) Arte, Vino y Viñas. La Cultura del Vino en el patrimonio Artístico de la DO Cariñena. Zaragoza, DPZ. Institución Fernando el Católico.

Aparicio, J.L., Alonso, L.J. y Sánchez, J.L. (2003) Los espacios vitivinícolas en Castilla y León: la evolución hacia un sistema productivo de calidad. Boletín de la AGE, 35, 101-122.

Asso, I. de (1748, reed. 1947) Historia de la Economía Política de Aragón. Zaragoza, CSIC.

Barco, E., Pérez Navarro, M.C. y Pinillos, M. (2006) Estrategias de diferenciación versus estrategias de tamaño. Cuadernos de Campo, 34, 12-16.

Bertrand, G. (2008) Un paisaje más profundo. De la epistemología al método. Cuadernos Geográficos, 43, 17-27.

Bielza, V., Loscertales, B. y Pardinilla, I. (2006) El proceso de comarcalización y el desarrollo sostenible del Somontano de Barbastro. Revista del Centro de Estudios del Somontano de Barbastro, 8, 113-140.

CAI. Servicio de Estudios (2006) El sector vitivinícola. La Industria Agroalimentaria aragonesa. Tres sectores representativos, 217244, Zaragoza, Caja de Ahorros de la Inmaculada.

Cambra, J. y Villafuerte, A. (2009) Denominaciones de origen e indicaciones geográficas: justificación de su empleo y valoración de su situación actual en España. En Lamo de Espinosa, J. (coord) El nuevo sistema agroalimentario en una crisis global, 329350, Almería Fundación Cajamar.

Casanova, J. (2008) Caracterización de variedades de vid (Vitis vinifera L) en la provincia de Huesca. Tesis Doctoral. Huesca, Uni- versidad de Zaragoza. Departamento de Agricultura y Economía Agraria.

Castelló, A., Frutos, L.M., Hernández Navarro, M.L., Loscertales, B. y Ruiz Budría, E. (2010) Los paisajes vitivinícolas en la economía rural aragonesa. Territorio, paisaje y patrimonio rural. Actas del XV Coloquio de Geografía Rural, 49-61, Cáceres. CD. ISBN 978-84-633-1988-8.

Castelló, A. y Giné, H. (2007) El Parque Cultural del Rio Vero: de espacio protegido a motor de desarrollo rural. En Molinero, F. (ed.) Espacios Naturales protegidos/Espaces naturels Protégés, 331-353, Valladolid. AGE/Universidad Internacional de Andalucía/Comité Nacional Français de Géographie. CD ISBN 978-84-691-1464-3.

Chueca, M.C. (1972) Sierras y valles del Sistema Ibérico al NW del Jalón. Zaragoza. CSIC. Instituto de Geografía Aplicada.

Climent, E. (2012) Alimentos de calidad y denominaciones geográficas en el sistema agroalimentario español. En Frutos, L.M. y Ruiz, E. (coords.) Los productos con indicación geográfica en el sistema agroalimentario español. Tradición y modernidad, 9-23, Zaragoza. DPZ. Institución Fernando el Católico.

Comision Europea (2000) Convention européenne du paysage. Raport. Florencia, 20/X/ 2000.

Cuadrat, J.M. (1999) El clima de Aragón. Zaragoza. CAI 100.

DGA (2008) Anuario de Estadística Agraria. Zaragoza, Diputación General de Aragón.

DGA. Servicio de Planificación y Análisis (2010) Análisis del sistema productivo Agroalimentario de Aragón. 2. El sector vitivinícola. Zaragoza. Diputación General de Aragón. 
Domingo, C. (2009) Las variedades autóctonas de vid. ACE. Revista Electrónica de Enología. Dossier, 111, 1-4.

Domingo, C. y Cuenca, J.M. (2005) Patrimonio e identidad para un espacio educativo multicultural. Análisis de concepciones y propuesta didáctica. Investigación en la Escuela, 56, 27-42.

Escalona, A.I., Loscertales, B. y Climent, E. (2009) Nuevos retos para el desarrollo territorial. Los espacios del vino y del calzado en la provincia de Zaragoza. Zaragoza, DPZ, Premios a la Investigación 2009 de Zaragoza Provincia. Cuarto Espacio (en prensa).

ESYRCE, (2005) Análisis de las Plantaciones de Viñedo. Madrid. MAPA, Secretaría General Técnica.

Estella, M.C. (1981) El viñedo en Aragón. Zaragoza. DPZ. Institución Fernando el Católico.

Estella, M.C. (1982) La producción y comercialización del vino de Cariñena. Zaragoza. DPZ. Institución Fernando el Católico.

Ferrer Regales, M. (1957) El Campo de Cariñena: estudio geográfico. Zaragoza. DPZ. Institución Fernando el Católico.

Francés, G. (2006) Turismo rural: las ventajas de la promoción y comercialización conjunta. Estudios Turísticos, 171, 105-114.

Frutos, L.M., Ruiz, E y Giné, H. (2008) Aragón. Atlas de Turismo y Desarrollo en el Mundo Rural. Vol. monográfico del Atlas Nacional de España. 206-217, Madrid, Instituto Geográfico Nacional.

Frutos, L.M. (1982) El campo en Aragón. Zaragoza. Ed. Librería General.

García, C.H. (2010) "Conservar la garnacha”, en Heraldo de Aragón, 20/08/2010.

García Manrique, E. (1960) Las comarcas de Borja y Tarazona y el Somontano del Moncayo. Zaragoza. CSIC. Instituto de Geografía Aplicada.
González, J.L. (1994) La vitivinicultura en España 1950-1981. MAPA. Madrid.

Graham, B., Ashworth, G.L. y Tunbridge, J.E. (2000): Geograpfy of Heritage. Power, Culture and Economy. London, Arnold.

Ilbery, B. (2001) Relocalización de los sistemas de producción agro-alimentaria en la Unión Europea. Geographicalia, 39, 5-20.

Lacarra, J.M. (1951) La Reconquista española y la repoblación del país. Zaragoza. Instituto de Estudios Pirenaicos. C.S.I.C.

Ledesma, M.L. (1967) La Encomienda de Zaragoza de la Orden de San Juan de Jerusalén en los siglos XII y XIII. Zaragoza. D.P.Z. Institución Fernando El Católico.

Lete Vela, M.J. (1998): El viñedo en el Campo de Borja y su flora infectante. Zaragoza. DPZ. Centro de Estudios Borjanos. Institución Fernando el Católico.

Lindkvist, K.B. y Sánchez, J.L. (2008): Conventions and innovation: a comparision of two localized natural resource-based industries. Regional Studies, 42(3), 343-354.

López Martín, F., Cabrera, M. y Cuadrat, J.M. (dirs, 2007) Atlas climático de Aragón. Zaragoza, Gobierno de Aragón.

Lorente, M. (2001) La fuerza de la diferencia. La Denominación de Origen, un instrumento para el desarrollo. Huesca, Ediciones La Val de Onsera.

Lorente, M. y Barbacil, J. (1004) Vinos de Aragón. Huesca, Ediciones La Val de Onsera.

Loscertales, B. (2009) La denominación de Origen Cariñena: una apuesta por la singularidad y la calidad en un mundo globalizado. Zaragoza. DPZ. Institución Fernando el Católico.

Mansfield, B. (2003) Fish, factory trawlers, and imitation crab: the nature of quality in the seafood industry. Journal of Rural Studies, 19, 9-21. 
Marías Cadenas, S. (2005): Viñas, tierras y bodegas. Cariñena, Consejo regulador de la DO Cariñena/Cajalón/DPZ. Institución Fernando el Católico.

Martínez, C. (2006) El Patrimonio Cultural: los nuevos valores, tipos, finalidades y formas de organización. Tesis Doctoral, Universidad de Granada, Departamento de Historia del Arte. [Libro en línea]. [Fecha de consulta: 25/02/2010]. <http://digibug.ugr.es/ handle/10481/1343>

Martínez, C. (2010) El vino aragonés da la vuelta al mundo. Surcos, 116, 6-11.

Martínez, J.M. y Vázquez, C. (2008) Paisaje cultural y desarrollo socioeconómico en un área desfavorecida: consideraciones éticas y estratégicas para un proyecto de musealización en el valle del río Cabriel. X COloquio Internacional de Neocrítica, Diez años de cambios en el mundo, en la Geografia y en las Ciencias Sociales, 19992008, Universidad de Barcelona, [Artículo en línea http://www.ub.es/geocrit/-xcol /249.htm]. [Fecha de consulta: 20/09/2010].

OSE Observatorio de la Sostenibilidad en España (2009) Patrimonio natural, cultural y paisajístico. Claves para la sostenibilidad. [Libro en línea]. [Fecha de consulta: 03/02/ 2010]. <http://www.sostenibilidad-es.org/ Observatorio+Sostenibilidad/esp/PubInd/Tematicos/Patrimonio/>

Pereira, G.M. (2006) La construction d'un paysage viticole: le Hautdouro, de Pombal è nos jours. Sud-Ouest Européen: Revue Géographique des Pyrénées et du Sud-Ouest, 21, 19-28.
Pintó i Fosalba, J. (2008) El paisaje de la viña. Valor cultural y ambiental. ACE. Revista Electrónica de Enología, 95, 1-7.

Rubio, P. (2010) El patrimonio rural. 3르 Ponencia, XV Coloquio de Geografía Rural. Cáceres.

Rubio, P. (2012) Los aceites de oliva con denominación de origen. En Frutos, L.M. y Ruiz, E. (coords.) Los productos con indicación geográfica en el sistema agroalimentario español. Tradición y modernidad, 43-72, Zaragoza. DPZ. Institución Fernando el Católico.

Rubio, P. y Hernando, P. (2007) Desarrollo local y patrimonio cultural. Los Parques Culturales. En Molinero, F. (ed.) Espacios Naturales protegidos/Espaces naturels Protégés, 331-353. Valladolid. AGE/Universidad Internacional de Andalucía/Comité Nacional Français de Géographie.

Sabaté, J. (2004) Paisajes culturales. El patrimonio como recurso básico para un nuevo modelo de desarrollo. Urban, 9, 8-29.

Sánchez, M. y Gil, J.M. (1997) Los vinos aragoneses con denominación de origen. Agricultura: Revista Agropecuaria, 777, 323-325.

Unwin, T. (2001) El vino y la viña. Geografía histórica de la viticultura y el comercio del vino. Barcelona, Tusquets.

Zouain, G. (2007) El patrimonio cultural en la construcción de indicadores de desarrollo. [Artículo en línea]. [Fecha de consulta: 15/03/2007]. <http://www.fundacioabertis.org/rcs_jor/zouain.pdf $>$ 